\title{
Locational Analysis of Public Health Facilities: A Case Study of Telok Panglima Garang, Selangor, Malaysia
}

\author{
${ }^{1}$ S.S.Radiah Shariff ; ${ }^{2}$ Mohd Omar ; ${ }^{3}$ Noor Hasnah Moin and ${ }^{4}$ David K. Smith \\ 1,2,3 Institute of Mathematical Sciences, Faculty of Science, University of Malaya, 50603 Kuala Lumpur, \\ Malaysia \\ 4 University of Exeter, Exeter, UK d.k.smith@exeter.ac.uk \\ *radiah@siswa.um.edu.my (Corresponding author). \\ Received on $13^{\text {th }}$ October 2009, accepted in revised form $10^{\text {th }}$ July 2010.
}

\begin{abstract}
As the economy and standard of living have improved, the demand has increased from the public for a better healthcare system. In developing countries like Malaysia, planning of public healthcare facilities is one of the keys for achieving an acceptable level of health. This is especially the case in rural areas. Location-allocation models can play a significant role in ensuring that facilities are accessible to the population. This study focuses on a selected area, Telok Panglima Garang, Selangor which is currently served by 5 public health facilities. The health delivery system in this area is analyzed in order to develop qualitative insights into the problem of ensuring that the local population has access to good healthcare. We identify variables like population coverage and average traveled distance by patients that influence the quality of the services. The existing public health delivery system is analyzed using both the Maximal Covering Location Problem (MCLP) and the $p$-median method. The limitations of the study and directions for future research are presented at the end of the paper.
\end{abstract}

(Keywords: Location Allocation Model, Public Healthcare Facilities, optimal coverage model)

\section{INTRODUCTION}

Locational analysis is a form of analysis done to investigate where to physically locate a set of facilities so as to optimize some objectives (such as to minimize the cost) of satisfying some sets of demands (customers or users of a service) subject to some sets of constraints. This form of analysis allows a decision-maker to analyze the facility location decisions which will affect a system's flexibility to meet these demands as they evolve over time.

Good location decisions are integral to a particular system's ability to satisfy its demand in an efficient manner. In health service planning, a locationallocation model plays a significant role as it provides a framework for investigating accessibility problems, comparing the quality (in terms of efficiency) of previous location decisions, and providing alternative solutions to change and improve the existing system (Rahman and Smith, 1999).

Proper provision for health is essential for economic development and because of that several studies on analyzing and evaluating the implementation of planning for health development have been done in other developing countries (for example, Wang for the World Bank, 2002).

The effectiveness of applying location analysis in many developing countries has been studied and yet to the best of our knowledge a comprehensive study of the Malaysian Health System has not been carried out. The first, and possibly the most important, problem in location modeling is to select a suitable objective function (Rushton, 1987). The most common assumption for public service facilities is to make the objective one that minimizes social cost; equivalently, one that maximizes social benefits (Hansen, 1980).

To achieve this, one of the most widely used model for location allocation problems, the $p$-median problem, (Hakimi, 1964) is utilized. The $p$-median problem can be stated as "Given discrete demands, locate a number of facilities so that total weighted traveled distance (or time) between facilities and demand points is minimized". An alternative model that is often used is the Maximal Covering Location Problem (MCLP) first introduced by Church and ReVelle in 1974.

The MCLP can be described as "To maximize coverage of health services (or to minimize the uncovered population) within a given travel 
distance (between facilities and demand points) using a fixed number of facilities".

Many previous studies that address locating health facilities in developing countries have considered both the $p$-median problem and the MCLP. Gould and Leinbach in 1966 studied the problem of locating hospitals and determining their capacities (in terms of number of beds) in the western part of Guatemala, with an objective to minimize the traveled distance between eighteen population centers and three-to-be located regional hospitals.

To find the site and size of the regional hospitals based on the existing road networks, the authors considered a $p$-median problem solved using a transportation algorithm. In addition, Mehretu et al. (1983) conducted a study to locate rural health clinics in Eastern Region of Upper Volta, (now Burkina Faso) with an objective to minimize average traveled distance subject to the constraint that no one travels more than $5 \mathrm{~km}$.

The problem was defined as $p$-median problem with maximum distance constraint. A modified $p$ median model which addressed accessibility and physician availability at the clinics simultaneously was used to solve the location problem in Mafraq, a district in Jordan (Tien and El Tell 1984). This study demonstrated the need for improvement in the allocation of the villages in the district to the clinics and the allocation of clinics to the existing health centres.

A similar study by Rahman and Smith (1999) in the deployment of health facilities in rural Bangladesh found the optimal locations of facilities for Health and Family Welfare Centres (HFWCs) in Thangail Thana, Bangladesh, by the $p$-median method. The study resulted in reducing the average distance traveled between villages and facilities by at least $26 \%$. Other forms of modeling the $p$-median problem such as single and hierarchical level and capacitated $p$-median have also been studied.

We refer the readers to Dokmeci (1977, 1979), Heller et al. (1989) and Cocking et al. (2006) for further details.Demonstrating the use of location analysis in healthcare planning in rural Colombia, Bennett et al. (1982) utilized the MCLP to determine the number of rural health centers from which (and for which) personnel would be recruited as health workers.

These centers also served as ambulance bases. The findings suggested only 24 health centers were necessary to have $90 \%$ of the population covered.
Rahman (1991) also formulated his study as MCLP and managed to solve the problem of locating the new facilities to be added to the existing health provision system. This study also suggested that if the location decision is not influenced by any geographic constraint, the solution would be more efficient.

The percentage of coverage was important in a study in Colombia by Eaton et al (1981), in which in order to find new sites to add into the existing system, the MCLP was considered. Current and Storbeck (1991) and Pirkul and Schilling (1991) have proposed capacitated versions of the classical covering models, which would be useful for health facility location planning with capacity constraints in developing nations. Both papers have shown that by allowing variations in the demand for services at the facilities, the problem can be solved directly as a capacitated location problem or by allocating health personnel according to the demand at the facility.

Many problems in developing nations could be represented as $p$-median problems as it is such an appropriate model. However, in reality some problems are not single criterion. There are several, possibly conflicting, objectives. Several studies, for example, have combined both $p$-median and MCLP to solve their problems.

A study on the effect of changes to communication links due to the rainy season in a tropical country, specifically concerning the location of health facilities in Suhum district, Ghana, was done by Oppong (1996). The problem was solved as both a $p$-median as well as an MCLP, opening ways to multi criteria decision analysis.

\section{Health Delivery System in Malaysia}

As Malaysia strives to be a developed country by year 2020, the demand for a better healthcare system has become more significant. Currently, the primary healthcare (PHC) service in Malaysia is among the best in the developing countries $(\mathrm{MOH}$ Annual Report 2005). In this country, the health delivery system can be described as a hierarchical system, with central facilities. A central facility is one for which people must travel to receive the service, or from which a service is provided to the whole community of interest (Rahman and Smith, 1999).

In the majority of countries, developed and developing, most healthcare systems are organized on a hierarchical system, in which, in the first level, 
a patient goes to see a doctor or nurse, relatively close to his or her home. If necessary, the patient attends a hospital, the second level in the system, which provides facilities that are not available from the first level.

Some patients will then progress to a third level of hierarchy that comprises specialist hospitals. At present, the Malaysian government policy on national health plans is based on a health care system with three levels of services that range from PHC to specialized care. PHC is a communitybased management of people with chronic and complex conditions, including pre-admission and post hospital care. It also includes people with disabilities and geriatrics living on their own.

The Malaysian PHC delivery system consists of Community Clinics (CCs), District Health Offices and Hospitals, State Health Department and Specialized Hospital and Medical College Hospital (SHMCH). CCs include Health Clinics (HC), Rural Clinics (RC), and Mobile Clinics (MC). The different levels of the health system in Malaysia are summarized in Figure 1.

\section{TYPE OF CARE}

HEALTH FACILITY

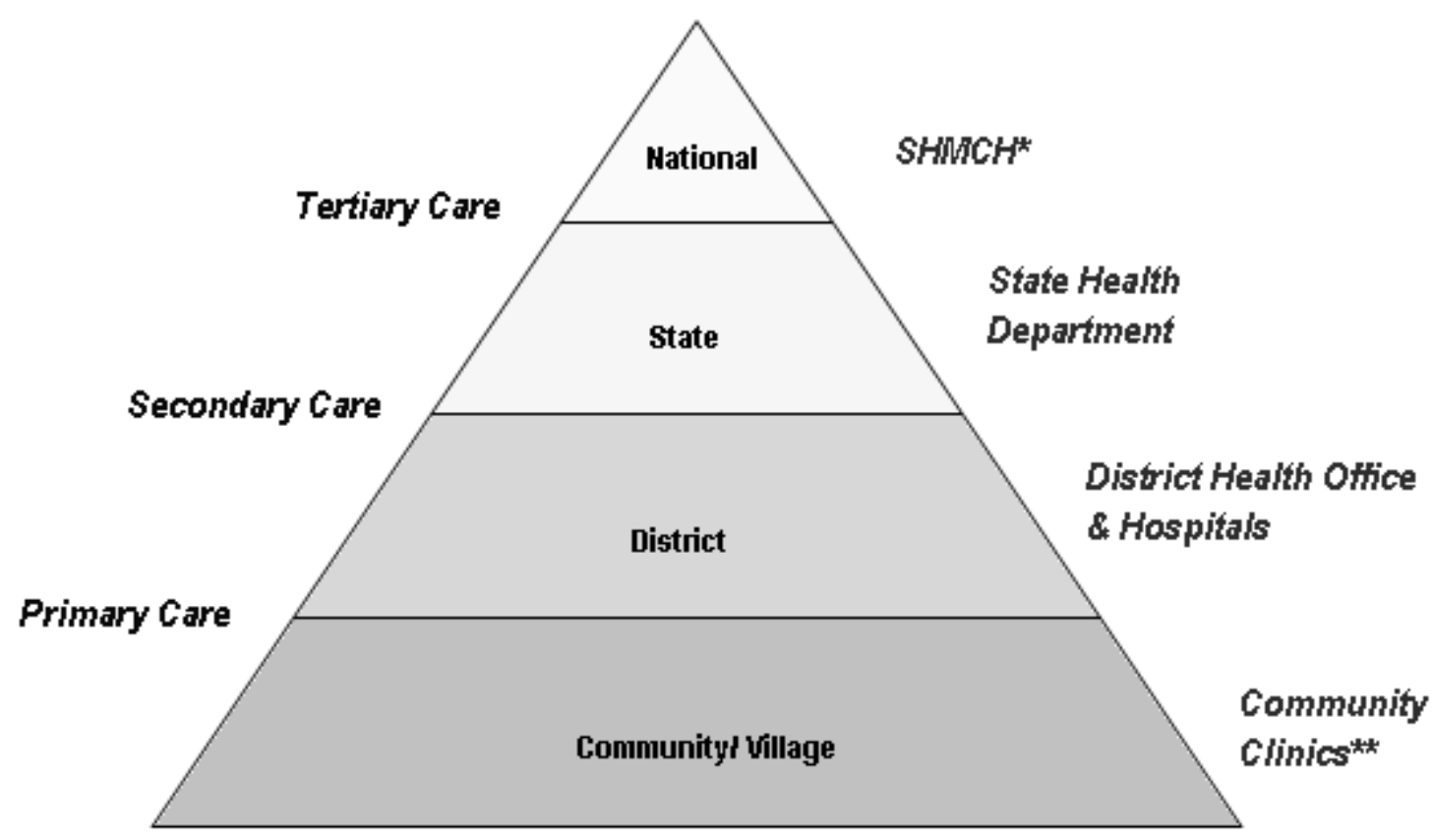

ADMINISTRATION LEVEL

"sHWCH - Specialized Hospital and Medical College Hospital

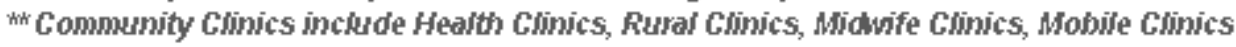

Figure 1: Hierarchy of public health care system in Malaysia.

In the Seventh Malaysia Plan, 1996--2000, (Economic Planning Unit, Prime Minister's Department, Malaysia, 1995) a comprehensive coverage of basic health services for rural and remote areas was given priority under the rural health program. It was planned through the construction of new primary health centers and clinics and by upgrading many of the rural, and maternal and child clinics to health clinics (HC).

These serve as the first contact point of patients with the public health system and should be equipped in basic imaging and laboratory diagnostic facilities and teleprimary IT systems. In the Ninth Malaysia plan, 2006-2010, (Economic 
Planning Unit, Prime Minister's Department, Malaysia, 2006), the emphasis continues to be on the provision of client-focused services and community needs in order to fulfill the demand for a better healthcare system.

It proposes greater integration of health services, focus on evidence-based, quality healthcare and the development and delivery of services that are appropriate to client and community needs. Currently, there are more than 800 health clinics and about 1920 community clinics (CCs) with 90 standalone maternal and child clinics nationwide.

The norm is to have one PHC for every 15,000 to 20,000 people and one CC for every 5000 in the population. From the Malaysian Ministry of Health $(\mathrm{MOH})$ record, $88.5 \%$ of population lives within 5 $\mathrm{km}$ of a health facility and $81 \%$ within $3 \mathrm{~km}$ (NST, 2007).

In this study, we carry out a preliminary study applying a location modeling for public health facilities in Malaysia by examining the existing public health facilities in Mukim Telok Panglima Garang, situated in the district of Kuala Langat, Selangor. The efficiency and the effectiveness of the past location decision is studied and analyzed.

This paper is organized as follows: A brief description of the location of the study is given in Section 2 and the model is described in Section 3. Section 4 presents the results and recommendations whilst the conclusion and proposals for future work are presented in the last section.

\section{Setting for this study}

Mukim Telok Panglima Garang is located about 27 $\mathrm{km}$ southeast of Shah Alam (the capital of the state of Selangor), and comprises a small town centre, a few medium-sized residential areas and villages as well as small to medium workshops and factories. At present, the area is served by two Health Clinics, which are Klinik Kesihatan Telok Panglima Garang (KK TPG) and Klinik Kesihatan Sijangkang (KK S) and 4 Rural Clinics (Klinik Desa- KD).

These Rural Clinics or Klinik Desa, also known as maternal and child clinics, serve mainly mothers and children between 0-6 years old. The service ranges from pre-natal check-ups, for the total nine months of pregnancy, to post-natal check-ups, after the delivery, including family planning. KK TPG has two sections, one is for maternal and child and the other for outpatients. KK S on the other hand only has the outpatient department. In this study, we will only consider the homogeneous types of facilities, which is the location of Rural Clinics.

Therefore, there are 5 units (1 KK and 4 KDs (Rural Clinics)), namely Telok Panglima Garang (TPG), Kampung Medan (KM), Kebun Baru (KB), Sijangkang Dalam (SD) and Sijangkang Luar (SL) for consideration. Figures 2 and 3 illustrate the various districts in Selangor and the location of the area under study, respectively.

The area of study is 8071 hectares in size, with total population of 66240 situated within a rectangular area of $2^{\circ} 54^{\prime} \mathrm{N}$ to $2^{\circ} 58^{\prime}$ and $101^{\circ} 26^{\prime} \mathrm{E}$ to $101^{\circ} 30^{\prime} \mathrm{E}$ (or $80.71 \mathrm{~km}^{2}$ ). The population in the study area is sparsely distributed and as mentioned earlier, there is a small town centre, few mediumsized residential areas and villages as well as small to medium size workshops and factories.

In addition, there is approximately 18 hectares or 24 percent of the area which is unpopulated, as there are chicken (poultry) and palm oil farms situated in this area. The population service coverage and the service boundary for each of these clinics have been determined by higher management in the District Health Office in Kuala Langat and are monitored by Staff in Charge (SIC), based in KK TPG.

The boundaries are determined based on population density, distance as well as accessibility. Each clinic is assigned a target population to service per year. For example for 2007, the target is 5 clinics to serve a total of 66240 people, with individual clinics serving between the minimum population of 6000 and the maximum of 23000 .

Some clinics are operating above their capacity. For example, Klinik Desa Sijangkang Luar (SL) is still operating in an old building that is the old midwife clinics building (RBK status) that can only accommodate 4000 patients per year. However, the unit is targeted to serve approximately 13000 patients in 2007 (JM Interview, 2007). For simplicity, in this study all facilities are assumed to be un-capacitated, as this experience shows that capacity is not a hard constraint. 


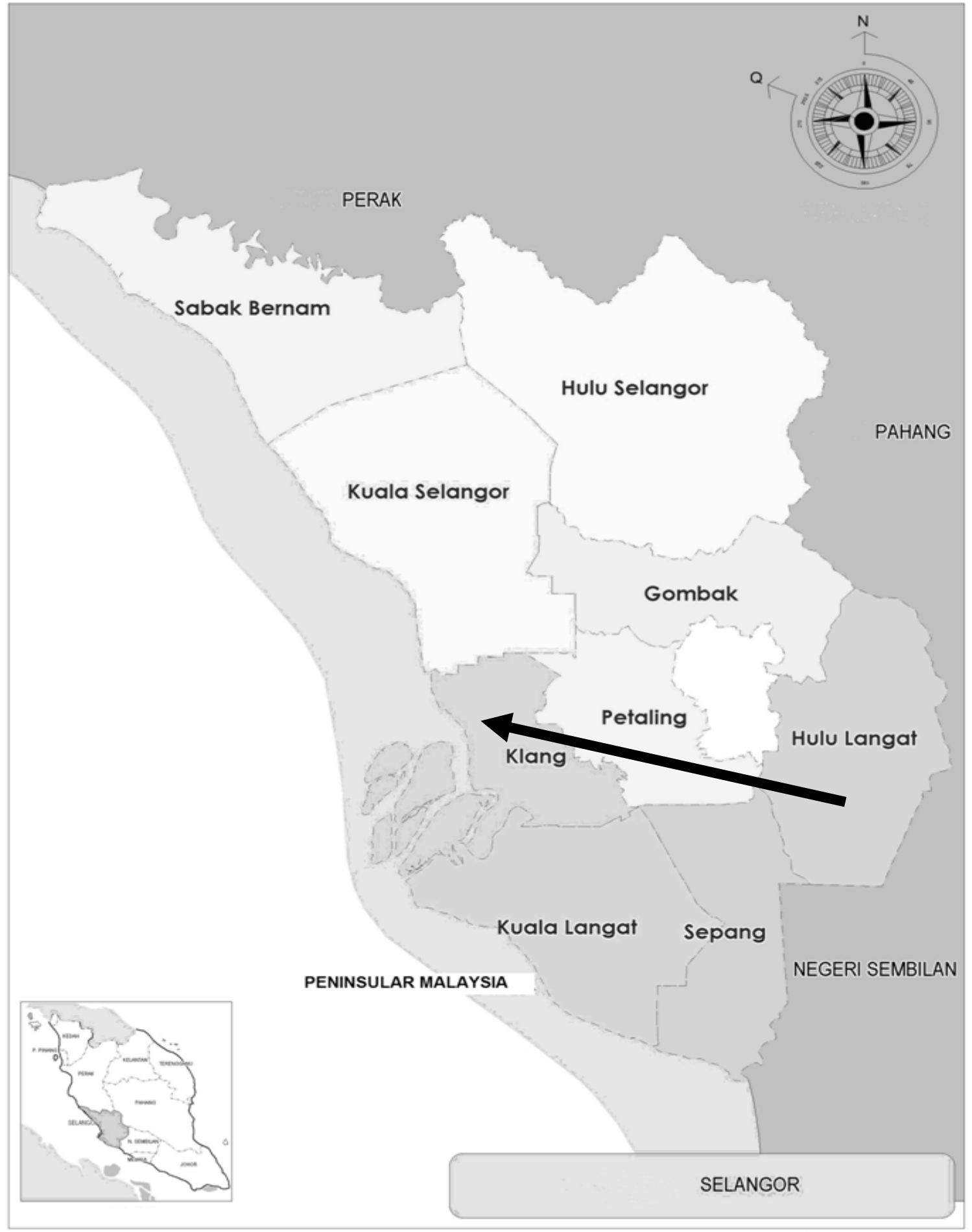

Figure 2: Map of Selangor indicating all the districts 


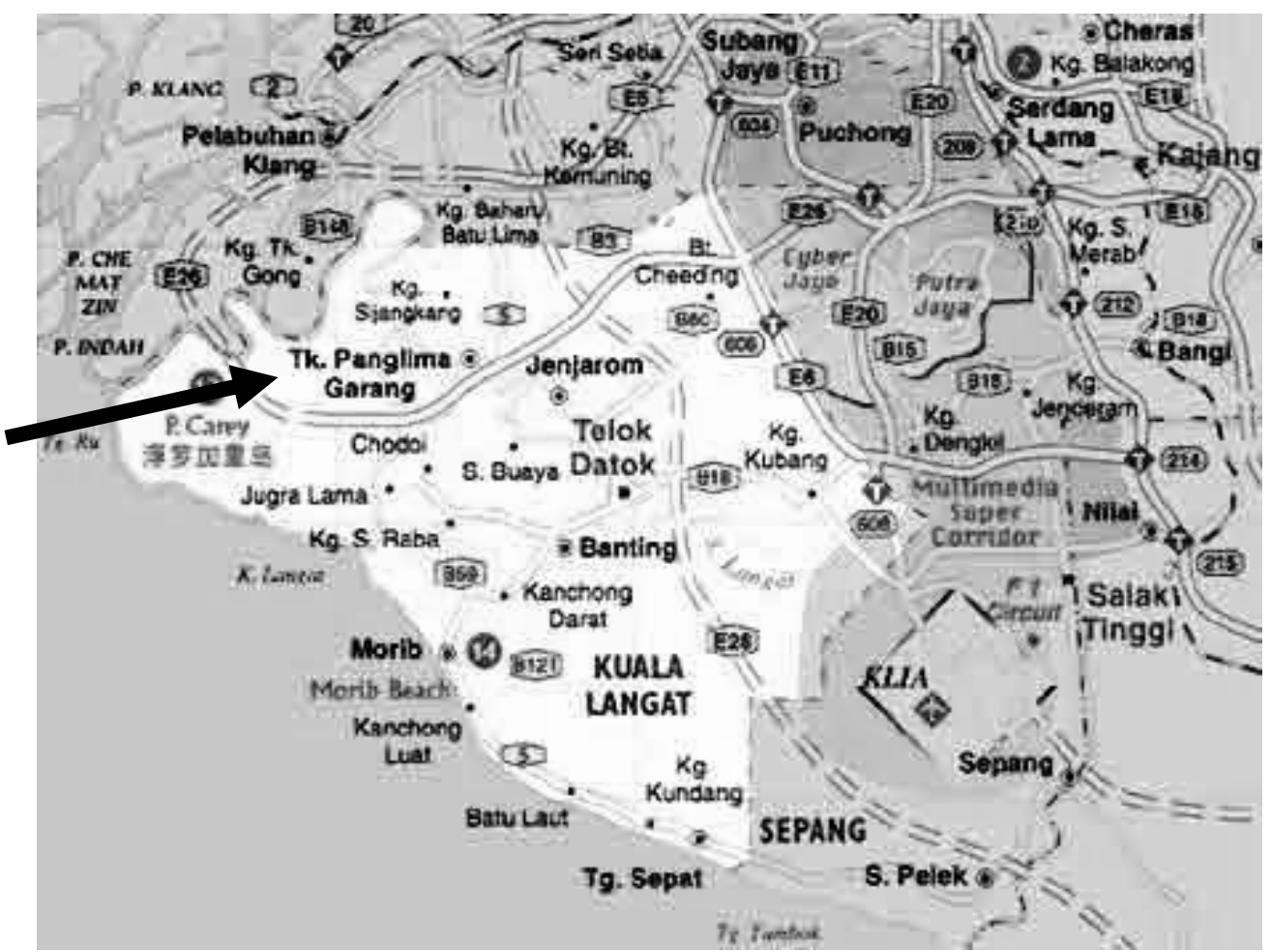

Figure 3: Map of Kuala Langat indicating Mukim Telok Panglima Garang

Table 1 summarizes the target population breakdown for the five clinics under study in Mukim Telok Panglima Garang. It also describes the breakdown of target service volume for every clinic, showing, for instance, the number of babies and the number of pregnant mothers that should go to clinics, and family planning provision. As mentioned earlier, Rural Clinics only serve mothers and children under six years old. Hence instead of total population of 66240 from Table 1, only 30458 are potential visitors to Rural Clinics.

Each Rural Clinic is 7 to $11 \mathrm{~km}$ apart from each other and located on a car track with very good road conditions. All clinics are easily accessible despite that there is no public transport available (except for TPG). Figures 4 and 5 indicate the service boundaries and the roads and tracks passable by car in the area under study.

It is assumed that the total population of 30458 is uniformly distributed within the area of study. The area comprises five service boundaries with different target population volume. The whole area is divided into 179 smaller sub regions, with their demand nodes located centrally and are approximately $1 \mathrm{~km}$ apart from each other. Figure 4 displays the locations of five clinics within the study area, together with the service boundary and the unpopulated regions. There are 47 nodes that fall into the unpopulated regions situated within the service areas of KB and TPG. It is also noted that the nodes, located in $\mathrm{KM}$, are assigned very high demand volume at more than 240 per node.

In order to reduce the high demand volume, the regions were further divided into smaller regions which are within approximately $0.5 \mathrm{~km}$ each and this result in an increase of the demand nodes from 179 to 221 nodes. The uniformity assumption of demand distribution in this study will be considered in two ways.

First, the population demand is uniformly distributed within its own service boundary where the demand volume for each node differs with the different service boundary regions. Table 2 summarizes the distribution of demand nodes and its demand volume. Secondly, the population demand is uniformly distributed within the whole area of study. In this case, every demand node will have the same demand volume $(30458 / 179=170)$. 
Table 1: Targets for consultations and health provision for Year 2007 (Telok Panglima Garang Health Clinics)

\begin{tabular}{|c|c|c|c|c|c|c|}
\hline & KKTPG & KD K/B & KD S/D & KD K/M & KD S/L & Total \\
\hline Birth in 2006 & 440 & 179 & 104 & 210 & 196 & 1129 \\
\hline Total Population & 22722 & 11128 & 5696 & 14109 & 12585 & 66240 \\
\hline$\%$ of total & 34.3 & 16.8 & 8.6 & 21.3 & 19 & 100 \\
\hline Live Birth & 425 & 206 & 105 & 262 & 233 & 1231 \\
\hline No of Babies & 639 & 311 & 159 & 395 & 352 & 1856 \\
\hline Children $0-1$ yrs & 598 & 291 & 149 & 370 & 330 & 1738 \\
\hline Children 1-2 yrs & 1182 & 578 & 296 & 733 & 653 & 3442 \\
\hline Children 1-4 yrs & 2271 & 1111 & 568 & 1408 & 1256 & 6614 \\
\hline Children 5-6 yrs & 856 & 443 & 227 & 562 & 554 & 2642 \\
\hline Pregnant Mothers & 483 & 238 & 121 & 306 & 269 & 1417 \\
\hline Birth at Residence & 3 & 1 & 1 & 2 & 2 & 9 \\
\hline Family Planning (New) & 98 & 47 & 24 & 61 & 53 & 283 \\
\hline Family Planning (Repeat) & 1510 & 790 & 404 & 1016 & 988 & 4708 \\
\hline Pap Smear & 280 & 144 & 73 & 183 & 180 & 860 \\
\hline Women (15-44 yrs) & 5178 & 2691 & 1377 & 3412 & 3364 & 16022 \\
\hline Milk Powder Recipients & 50 & 24 & 12 & 31 & 31 & 148 \\
\hline House Visit & 4003 & 2681 & 1065 & 2038 & 2601 & 12388 \\
\hline
\end{tabular}

Potential Population That

Should Go to KD

10085

5114

2617

6485

6157

30458 
Malaysian Journal of Science 29 (2): 98-118 (2010)

Table 2: Demand Nodes Distribution

\begin{tabular}{|c|c|c|c|c|c|c|}
\hline $\begin{array}{l}\text { Service } \\
\text { Area }\end{array}$ & $\begin{array}{l}\text { Number } \\
\text { Node }\end{array}$ & & Demand & $\begin{array}{l}\text { Volume } \\
\text { Node }\end{array}$ & per & Demand \\
\hline SD & & 20 & & & 131 & \\
\hline SL & & 32 & & & 192 & \\
\hline KM & & 26 & & & 249 & \\
\hline $\mathrm{KB}$ & & 46 & & & 111 & \\
\hline TPG & & 55 & & & 183 & \\
\hline Total & & 179 & & & & \\
\hline SD & & 20 & & & 131 & \\
\hline SL & & 32 & & & 192 & \\
\hline KM & & 45 & & & 144 & \\
\hline KB & & 46 & & & 111 & \\
\hline TPG & & 78 & & & 129 & \\
\hline Total & & 221 & & & & \\
\hline
\end{tabular}

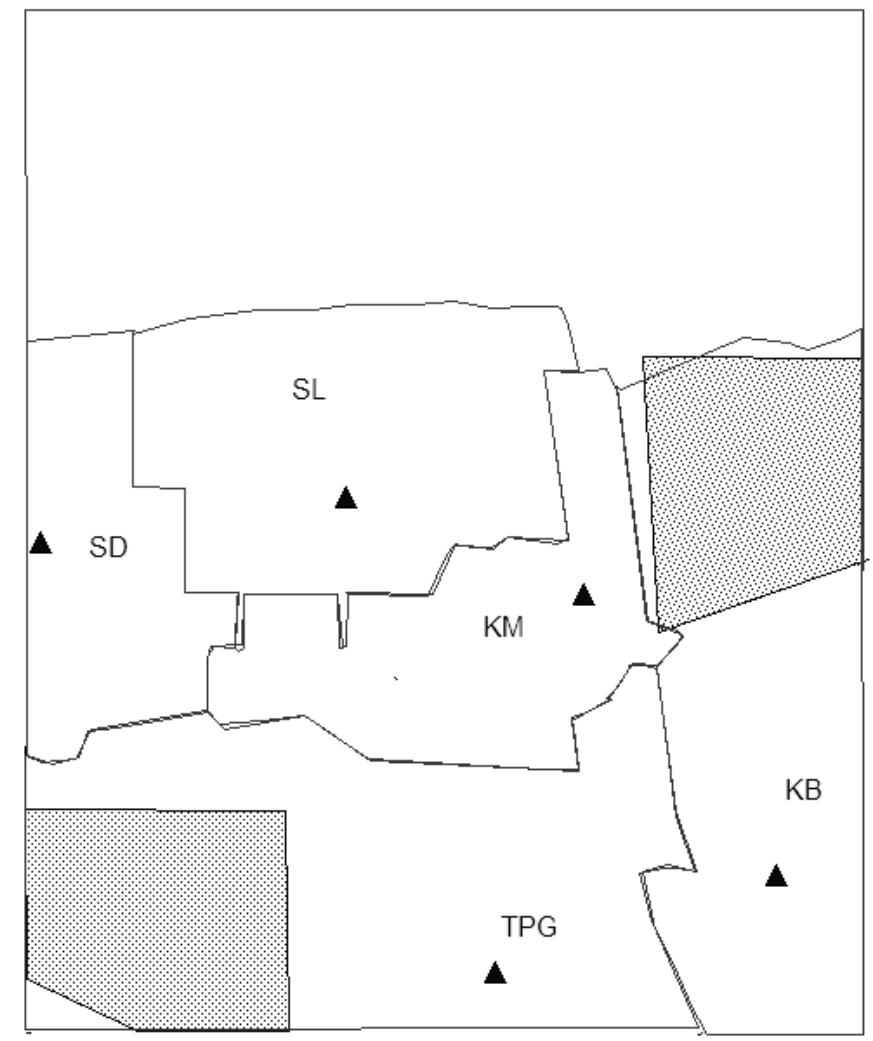

Figure 4: Map of Telok Panglima Garang indicating the service boundaries for all 5 rural clinics and the unpopulated regions 


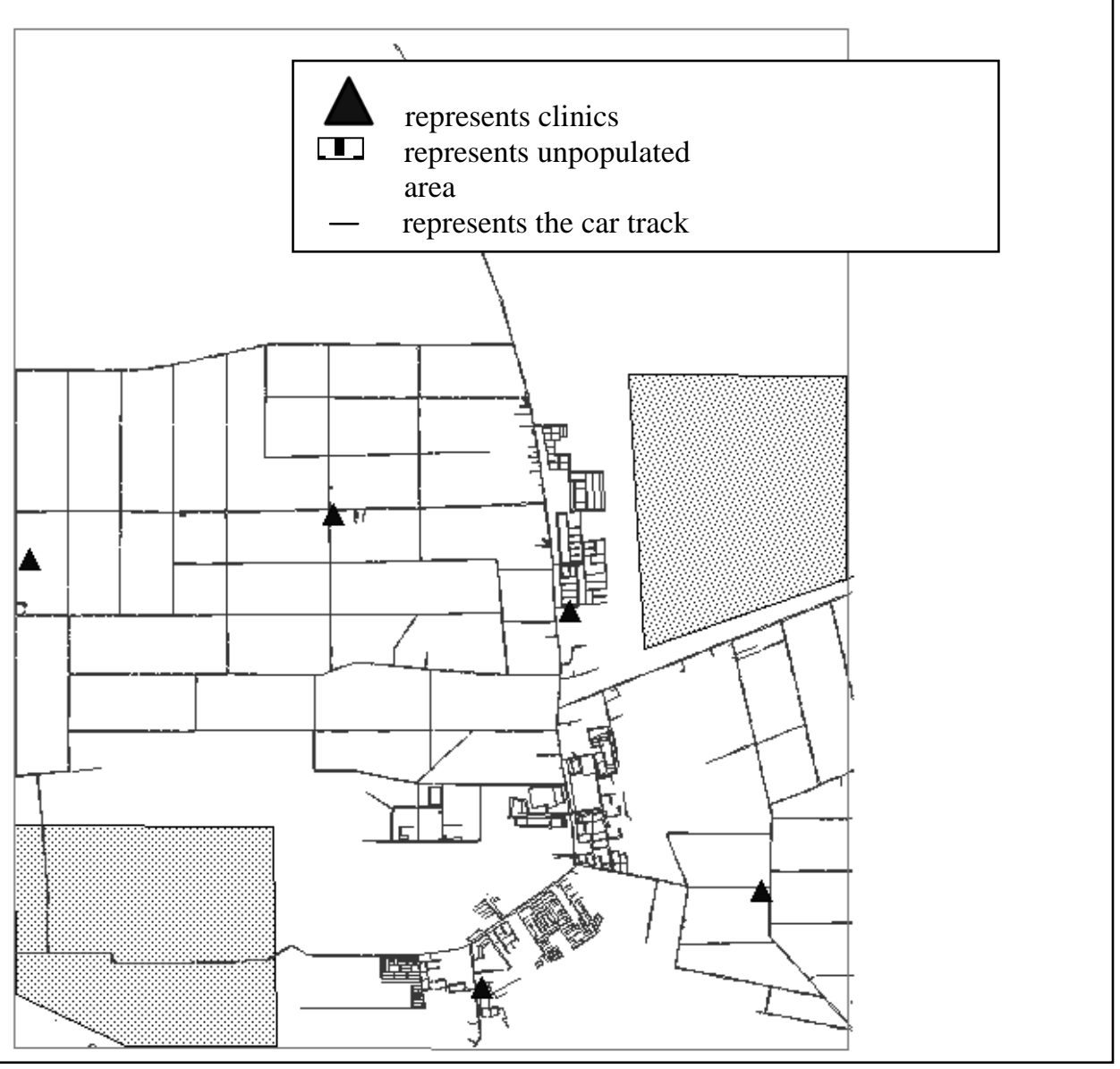

Figure 5: Map of Telok Panglima Garang indicating car roads and tracks together with the locations of 5 rural clinics

\section{Model}

The need for the National Health policy was identified in the midterm review of the Sixth Malaysia Plan, 1991-1995 (Economic Planning Unit, Prime Minister's Department, Malaysia, 1990) which gave the priority to comprehensive coverage of basic health services for rural and remote areas (MOH Annual Report 2005). In view of this, the maximum covering location problem (MCLP) is first considered.

The following formulation, adapted from Pirkul and Schilling (1991) is used to model the problem. The sets $I$ and $J$ represent the clients and sites for facilities respectively. Variable $x_{i j}$ is 1 if client $i$ is assigned to facility $j, y_{j}$ is 1 if a facility is sited at $j$ and $c_{i j}$ is 1 if the demand volume $a_{i}$ is assigned to a facility within the coverage distance $S$, where $S$ is the maximum service distance or time. $a_{i}$ is the

demand volume at demand node $i$ and $d_{i j}$ is the distance between demand node $i$ and facility $j$. The objective maximizes the total population assigned to a facility within the coverage distance $S$.

Constraint (1) limits the total number of facilities to no more than $p$, while constraint (2) ensures that all demand nodes are assigned to a facility. The level of service provided to covered demand is obviously controlled by $S$; however, an uncovered demand node could be assigned to any available facility, regardless of its proximity.

Constraint (3) guarantees that a demand node is only allocated to an open facility. Constraints (4) and (5) fix the locations of the facilities that already exist and impose the integrality restriction respectively. Note that the value of $p$ is the total number of facilities, including both existing facilities and facilities that are to be located. 
Maximize $\quad \sum_{i \in I} \sum_{j \in J} c_{i j} a_{i} x_{i j}$

Subject to

$$
\begin{array}{ll}
\sum_{j \in J} y_{j} \leq p, & \forall \quad j \in J \\
\sum_{j \in J} x_{i j}=1, & \forall \quad i \in I \\
x_{i j} \leq y_{j} & \forall \quad i \in I, j \in J \\
y_{j}=1 & \text { for all existing facilities } \\
x_{i j}, y_{j}=[0,1] & \forall i \in I, j \in J
\end{array}
$$

where

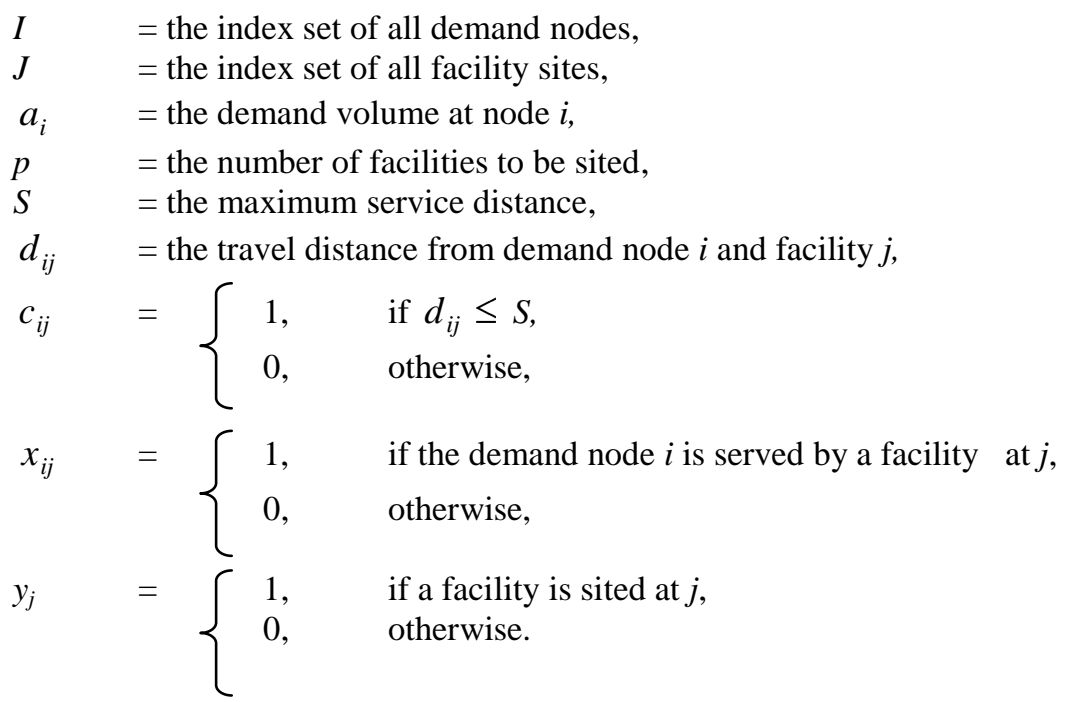

Another important factor that is always considered in any location allocation model for public health is minimizing the total travel distance between demand nodes and the facilities, known as the $p$ median problem. We use the following formulation, (ReVelle and Swain, 1970) in which the objective of the problem is to minimize the total distance which people must travel to the facilities to get the service. Instead of limiting the total number of facilities to no more than $p$ as in the MCLP, constraint (6) fixes the number of facilities to $p$.

Minimize $\quad \sum_{i \in I} \sum_{j \in J} a_{i} d_{i j} x_{i j}$ 


$$
\begin{array}{ll}
\sum_{j \in J} y_{j}=p, & \forall j \in J \\
\sum_{j \in J} x_{i j}=1, & \forall i \in I \\
x_{i j} \leq y_{j} & \forall i \in I, j \in J \\
x_{i j}, y_{j}=[0,1] & \forall i \in I, j \in J
\end{array}
$$

\section{RESULTS AND DISCUSSION}

\section{Locational efficiency based on average distance traveled}

I. The population demand is uniformly distributed within its own service boundary

The first analysis is carried out on the 179 and 221 numbers of nodes, respectively. The results are summarized in Table 3. It is observed that the average traveled distance decreases from $3.34 \mathrm{~km}$ (one facility) to $1.48 \mathrm{~km}$ ( 5 facilities) for the 179 nodes whilst it decreases from $3.40 \mathrm{~km}$ to $1.49 \mathrm{~km}$ for the 221 nodes.

On average every additional facility improves the average traveled distance between 10 to 31 percent for both cases. Figure 6 depicts similar decreasing trend of average distance traveled when demand is distributed uniformly within its own service boundary for both cases.

II. The population demand is uniformly distributed within the whole area of study

In this study the locational efficiency is analyzed by formulating the problem as the MCLP where the objective function is to maximize the percentage of population covered within some maximum allowable distance, $S$. Although the national health policy does not specify any maximum allowable distance, two values are considered, which are 3 and $5 \mathrm{~km}$, respectively, as recorded by $\mathrm{MOH}$.

An analysis which is similar to Section 4.1 is carried out. Tables 5 and 6 tabulate results for the first case where the population demand is distributed uniformly within the service boundary area. It is observed that the choice of facilities to be
As the demand volume are equally divided among all the nodes, the analysis for this case is considered based on the 179 nodes and 132 nodes where all the 47 nodes located in the unpopulated regions are assigned a demand volume of 0 . Note that this has resulted in an increase in demand volume for each node from 170 to 230 .

Similarly, as shown in Table 4 that the average traveled distance decreases with the increase in the number of facilities. It is observed that the average traveled distance decreases from $3.75 \mathrm{~km}$ to only $1.89 \mathrm{~km}$ when all the five facilities are opened (179 nodes) and the results are even better when the unpopulated regions are excluded from the analysis.

This is because the unpopulated areas are located furthest from the facilities. It is noted that every additional facility improves (by reduction) the average traveled distance by 10 to 24 percent. Figure 7 depicts the same decreasing trend of average traveled distance when demand is distributed uniformly within the whole study area.

\section{Locational Efficiency Based On Percentage of Population Coverage}

opened is exactly the same for the 179 and 221 nodes. Due to more scattered distribution of demand in 221 nodes, the population coverage is higher at $99.4 \%$ when only two facilities are open.

This might be due to the demand volume being more scattered at the facility area. Figure 8 and 9 illustrate the coverage trend. It is worth noting number of facilities required to achieve full coverage increases to 5. If only one facility is open, $100 \%$ coverage can only be realized when $S=7$ $\mathrm{km}$. Figure 10 depicts the trend in number of facilities and maximum allowable distance $S$ in achieving full coverage. 
Table 3: Percentage of Improvement in Average Traveled Distance with the Increase of Number of Facilities when demand is uniformly distributed within the service boundary

\begin{tabular}{cccccc}
\hline $\begin{array}{l}\text { Number of } \\
\text { Nodes }\end{array}$ & $\begin{array}{l}\text { Number of } \\
\text { Facilities }\end{array}$ & $\begin{array}{l}\text { Total Distance } \\
\text { Traveled (in } \\
\text { thousands) }\end{array}$ & $\begin{array}{c}\text { Percentage of } \\
\text { Improvement }\end{array}$ & $\begin{array}{l}\text { Average } \\
\text { Traveled } \\
\text { Distance (in km) }\end{array}$ & Open Facility \\
\hline 179 & 1 & 102 & - & 3.34 & KM \\
& 2 & 70 & 31.4 & 2.29 & SL, TPG \\
& 3 & 57 & 18.6 & 1.88 & SL,KB,TPG \\
& 4 & 50 & 12.3 & 1.64 & SL,KM,KB,TPG \\
& 5 & 45 & 10.0 & 1.48 & SD,SL,KM,KB,TPG \\
\hline 221 & 1 & 104 & & & KM \\
& 2 & 70 & 32.4 & 2.30 & SL,TPG \\
& 3 & 57 & 18.0 & 1.89 & SL,KB,TPG \\
& 4 & 50 & 12.5 & 1.65 & SL,KM,KB, TPG \\
& 5 & 45 & 9.8 & 1.49 & SD,SL,KM,KB,TPG \\
\hline
\end{tabular}

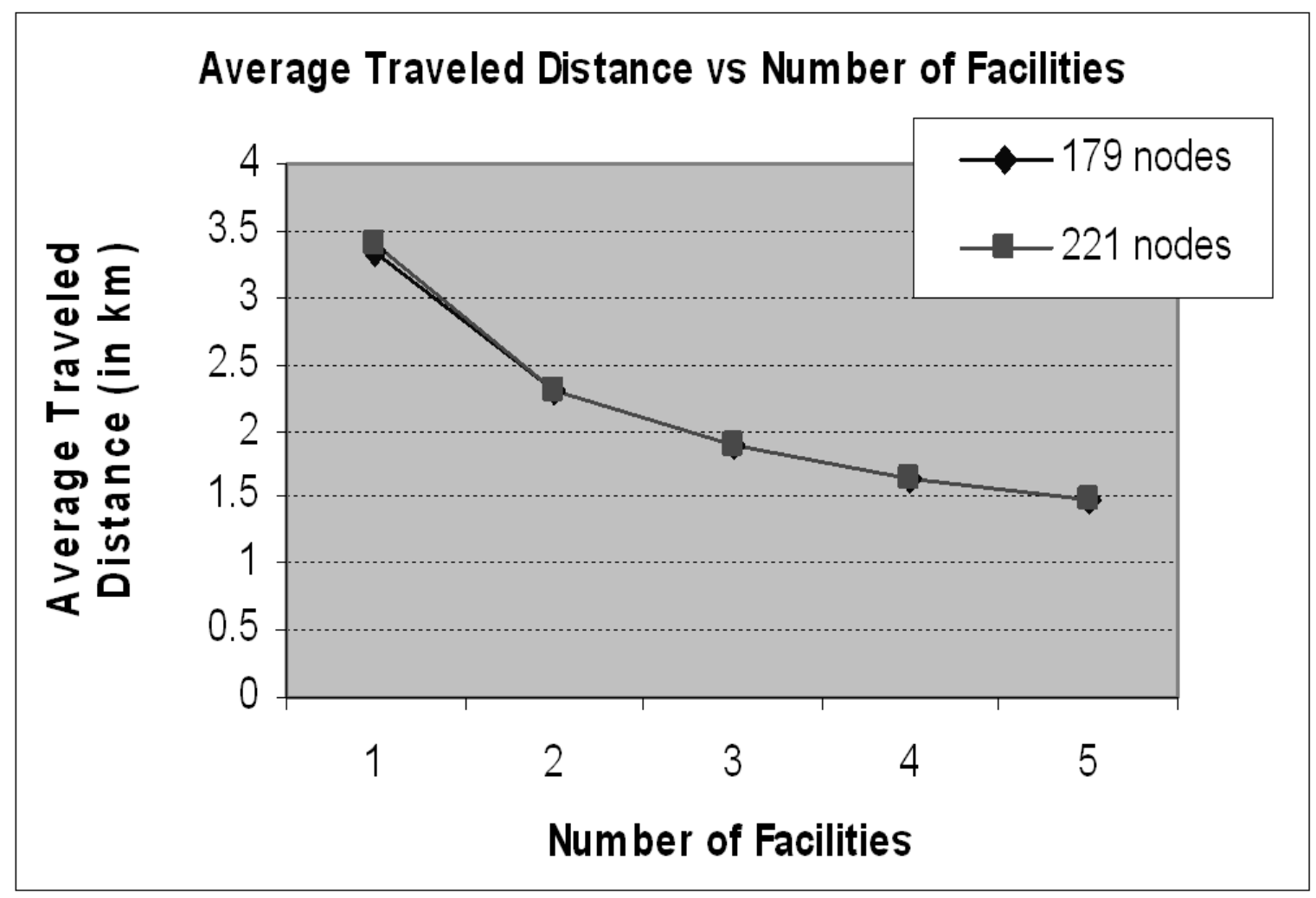

Figure 6: Trend in Average Traveled Distance when Demand is distributed uniformly within its own service boundary 
Table 4: Percentage of Improvement in Average Traveled Distance with the Increase of Number of Facilities when demand is uniformly distributed within the whole study area

\begin{tabular}{llllll}
\hline $\begin{array}{l}\text { Total } \\
\text { number } \\
\text { of }\end{array}$ & $\begin{array}{l}\text { Number of } \\
\text { nodes }\end{array}$ & $\begin{array}{l}\text { Total distance } \\
\text { traveled (in } \\
\text { thousands) }\end{array}$ & $\begin{array}{l}\text { Percentage of } \\
\text { Improvement }\end{array}$ & $\begin{array}{l}\text { Average } \\
\text { Traveled } \\
\text { Distance (in } \\
\text { km) }\end{array}$ & Open Facility \\
\hline 179 & 1 & 114 & - & 3.75 & KM \\
& 2 & 87 & 24.2 & 2.84 & SD,KM \\
& 3 & 71 & 17.8 & 2.34 & SL,KM,TPG \\
& 4 & 64 & 10.5 & 2.09 & SD,SL,KM, TPG \\
& 5 & 57 & 10.2 & 1.89 & SD,SL,KM,KB,TPG \\
& 1 & & & & \\
\hline 132 & 108 & - & 3.53 & KM \\
& 2 & 73 & 32.4 & 2.41 & SL, KB \\
& 3 & 63 & 13.7 & 2.06 & SL,KB,TPG \\
& 4 & 54 & 14.3 & 1.77 & SD,SL,KB,TPG \\
& 5 & 47 & 13.0 & 1.54 & SD,SL,KM,KB,TPG \\
\hline
\end{tabular}

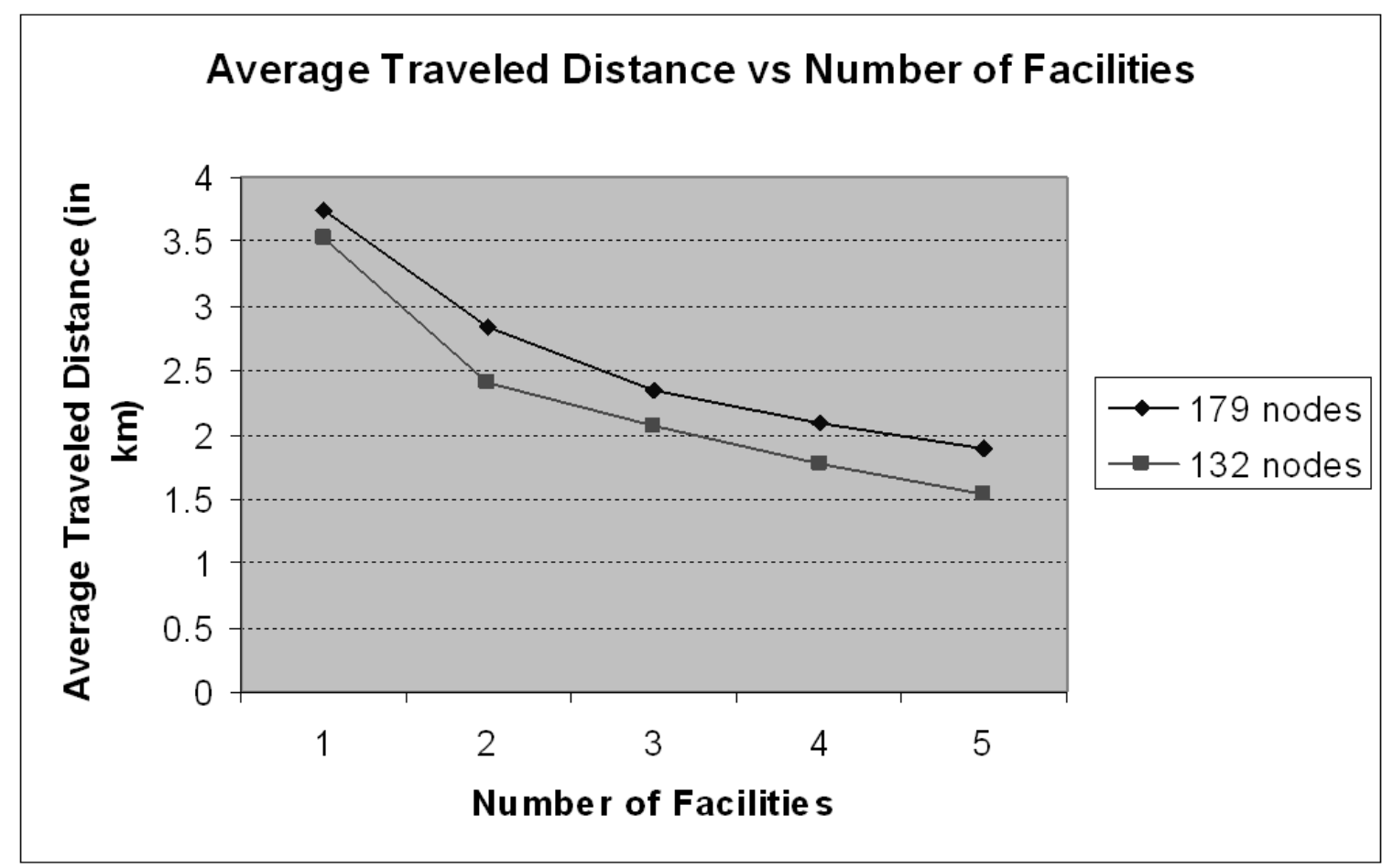

Figure 7: Trend in Average Traveled Distance when Demand is distributed uniformly over the whole service area 
As shown in Table 7 and Table 8 the highest coverage of only $99.4 \%$ is achieved when the population is distributed uniformly over the whole area of study. The trend in coverage percentage for both values of $S$ is illustrated in Figure 11 and 12 .

Further analysis shows that all the uncovered nodes fall in the unpopulated areas. Consequently, full coverage is obtained when the nodes in the unpopulated area are assigned a demand of zero.
Figure 13 illustrates the trend in number of facilities and maximum allowable distance $S$ in achieving full coverage.

As in the first case, full coverage is achieved if only one facility is open is when the maximum allowable distance $S$ in $7 \mathrm{~km}$. On the other hand, full coverage is not achieved in all circumstances.

Table 5: Coverage Percentage when demand nodes are uniformly distributed within service boundary only $(S=5 \mathrm{~km})$

\begin{tabular}{|c|c|c|c|c|}
\hline $\begin{array}{c}\text { Total Number of } \\
\text { Nodes }\end{array}$ & $\begin{array}{l}\text { Number of } \\
\text { Facilities }\end{array}$ & $\begin{array}{c}\text { Objective Function } \\
\text { Value }\end{array}$ & $\begin{array}{c}\text { Coverage } \\
\text { Percentage }\end{array}$ & Open Facility \\
\hline \multirow[t]{5}{*}{179} & 1 & 26963 & 88.5 & KM \\
\hline & 2 & 30085 & 98.8 & SL,KB \\
\hline & 3 & 30458 & 100 & SD,KM,TPG \\
\hline & 4 & 30458 & 100 & SD,SL,KM, TPG \\
\hline & 5 & 30458 & 100 & $\mathrm{SD}, \mathrm{SL}, \mathrm{KM}, \mathrm{KB}, \mathrm{TPG}$ \\
\hline \multirow[t]{5}{*}{221} & 1 & 26587 & 87.3 & $\overline{\mathrm{KM}}$ \\
\hline & 2 & 30270 & 99.4 & SL,KB \\
\hline & 3 & 30458 & 100 & SD,KM,TPG \\
\hline & 4 & 30458 & 100 & SD,SL,KM, TPG \\
\hline & 5 & 30458 & 100 & $\mathrm{SD}, \mathrm{SL}, \mathrm{KM}, \mathrm{KB}, \mathrm{TPG}$ \\
\hline
\end{tabular}




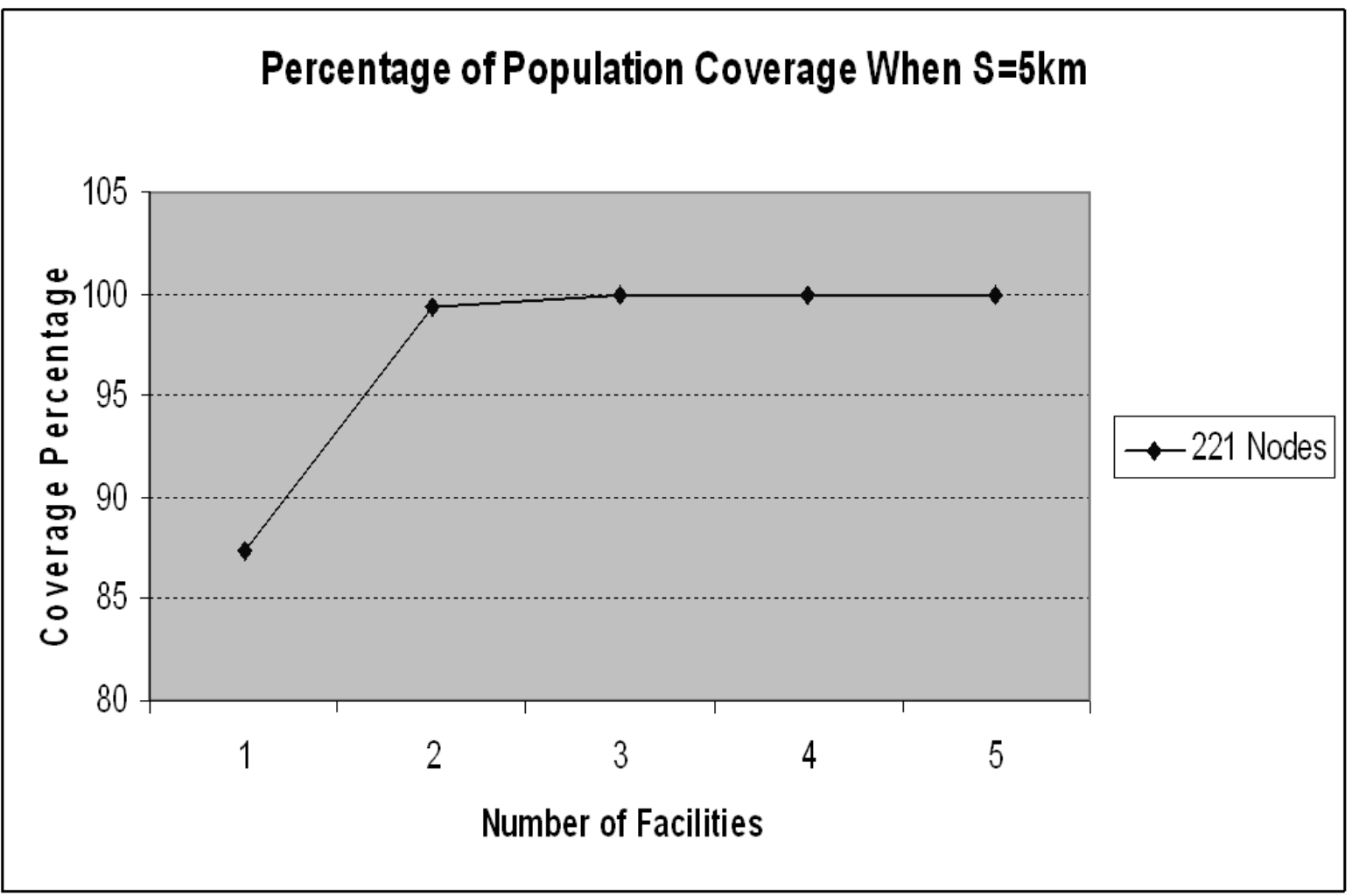

Figure 8: Trend in Coverage Percentage When $S=5 \mathrm{~km}$

Table 6: Coverage Percentage when demand nodes are uniformly distributed within service boundary only $(S=3 \mathrm{~km})$

\begin{tabular}{lllll}
\hline $\begin{array}{l}\text { Total Number of } \\
\text { Nodes }\end{array}$ & $\begin{array}{l}\text { Number of } \\
\text { Facilities }\end{array}$ & $\begin{array}{l}\text { Objective Function } \\
\text { Value }\end{array}$ & $\begin{array}{l}\text { Coverage } \\
\text { Percentage }\end{array}$ & Open Facility \\
& & & \\
\hline 179 & 1 & 12809 & 42.1 & KM \\
& 2 & 23273 & 76.4 & SD,KM \\
& 3 & 27437 & 90.1 & SD,KM,TPG \\
& 4 & 95.7 & SD,SL,KM, TPG \\
& 5 & 30458 & 100 & SD,SL,KM,KB,TPG \\
& & & & \\
\hline 221 & 1 & 39.9 & SL \\
& 2 & 76.3 & SL,TPG \\
& 3 & 23251 & 90.0 & SL,KB,TPG \\
& 4 & 27417 & 95.6 & SD,SL,KB, TPG \\
& 5 & 30318 & 99.5 & SD,SL,KM,KB,TPG
\end{tabular}




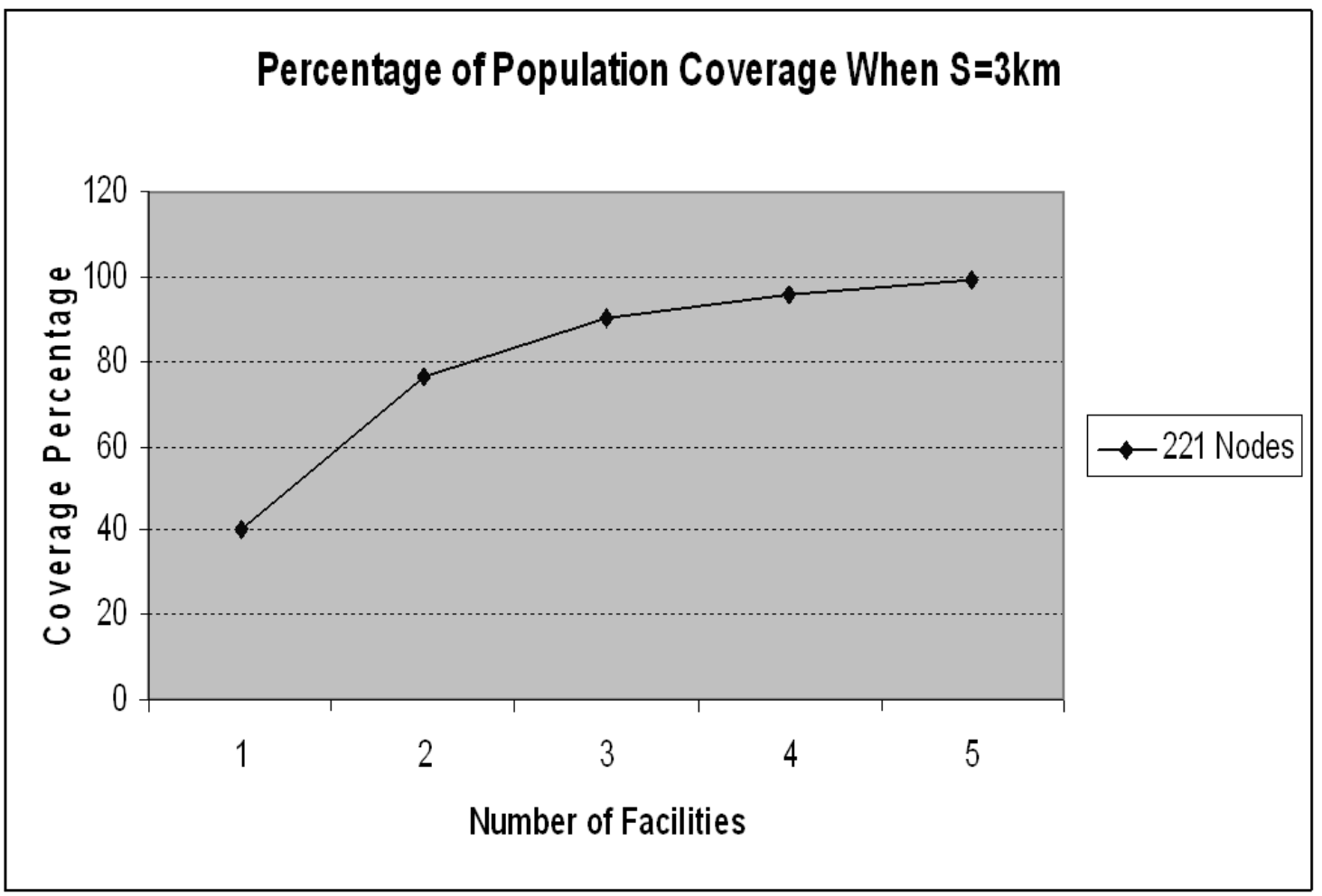

Figure 9: Trend in Coverage Percentage When $S=3 \mathrm{~km}$

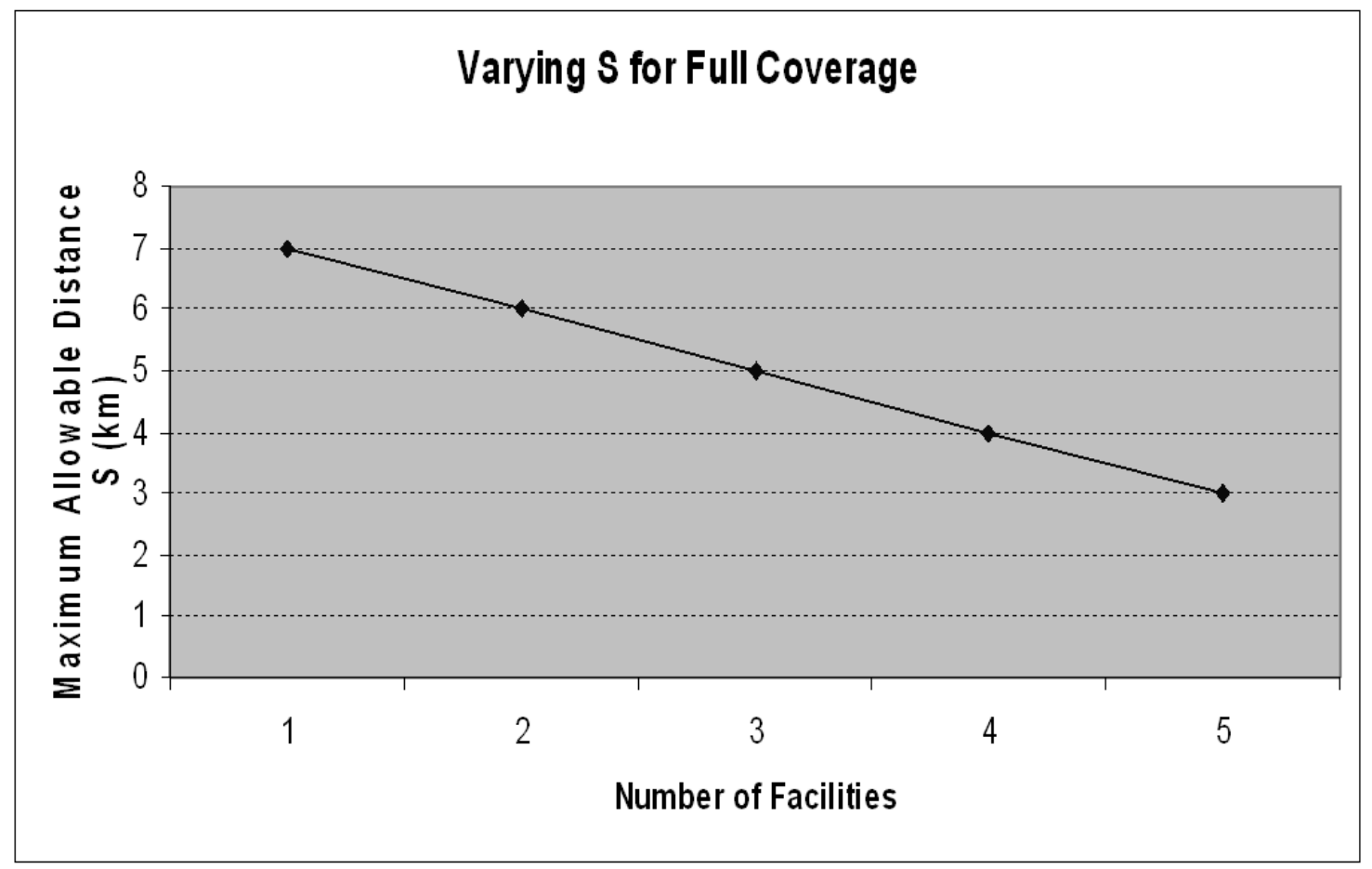

Figure 10: Maximum Allowable Distance $S$ for Full Coverage (when demand is distributed uniformly within the service boundary) 
Malaysian Journal of Science 29 (2): 98-118 (2010)

Table 7: Coverage Percentage when demand is uniformly distributed over the whole study area $(S=5 \mathrm{~km})$

\begin{tabular}{lllll}
\hline $\begin{array}{l}\text { Number of } \\
\text { nodes }\end{array}$ & $\begin{array}{l}\text { Number of } \\
\text { Facilities }\end{array}$ & $\begin{array}{l}\text { Objective Function } \\
\text { Value }\end{array}$ & $\begin{array}{l}\text { Coverage } \\
\text { Percentage }\end{array}$ & Open Facility \\
& 1 & & \\
\hline 179 & 22788 & 74.8 & KM \\
& 3 & 28925 & 95.0 & SD,KM \\
& 30287 & 99.4 & SD,KM,TPG \\
& 5 & 30287 & 99.4 & SD,SL,KM, TPG \\
& 30287 & 99.4 & SD,SL,KM,KB,TPG \\
& 1 & & & \\
\hline 132 & 25157 & 92.6 & KM \\
& 3 & 29997 & 100 & SD,KM \\
& 4 & 30458 & 100 & SD,KM,TPG \\
& 5 & 30458 & 100 & SD,SL,KM, TPG \\
& 30458 & & SD,SL,KM,KB,TPG
\end{tabular}

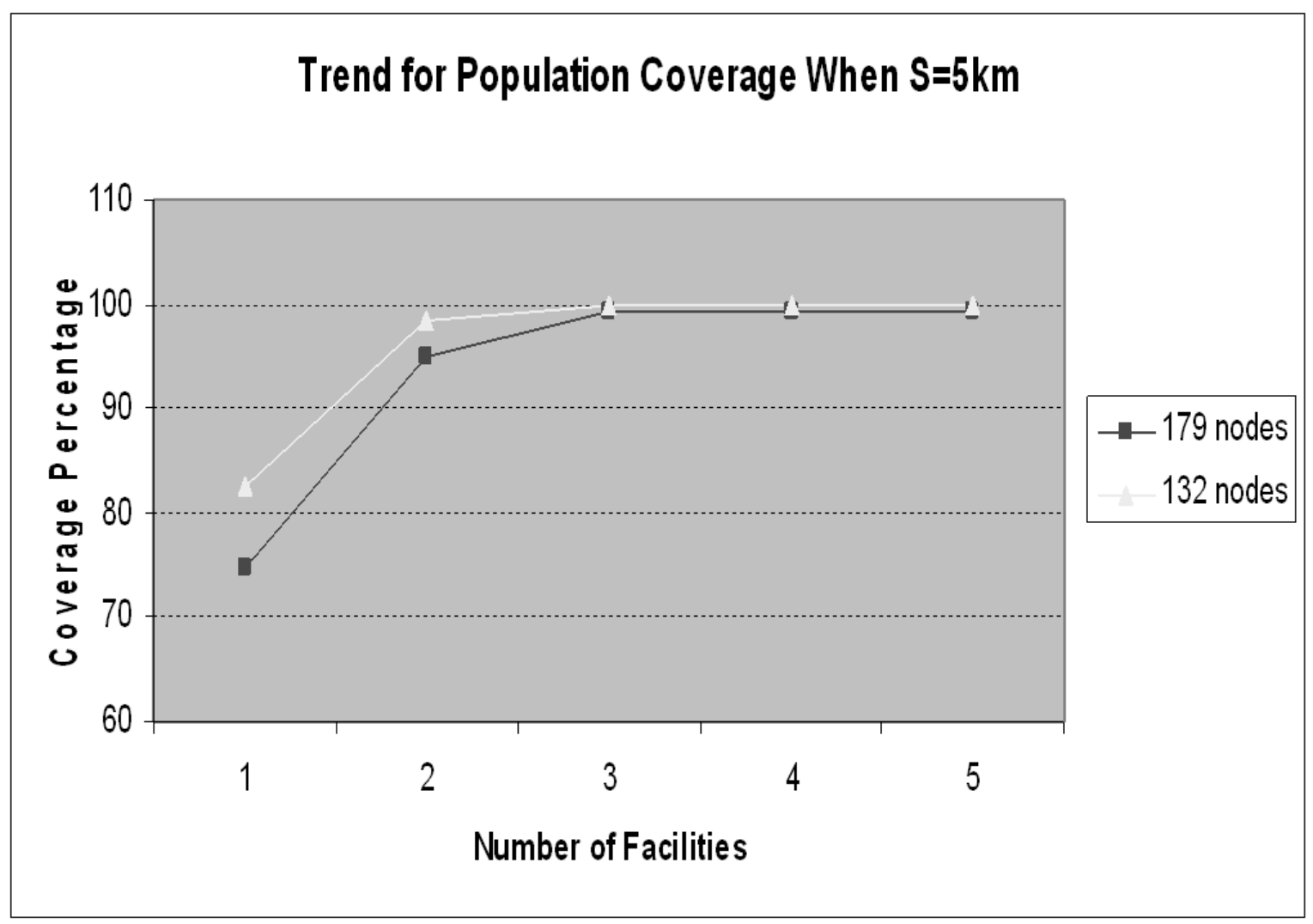

Figure 11: Trend in Coverage Percentage When $S=5 \mathrm{~km}$ 
Malaysian Journal of Science 29 (2): 98-118 (2010)

Table 8: Coverage Percentage when demand is uniformly distributed over the whole study area $(S=3 \mathrm{~km})$

\begin{tabular}{lllll}
\hline $\begin{array}{l}\text { Total number of } \\
\text { nodes }\end{array}$ & $\begin{array}{l}\text { Number of } \\
\text { Facilities }\end{array}$ & $\begin{array}{l}\text { Objective Function } \\
\text { Value }\end{array}$ & $\begin{array}{l}\text { Coverage } \\
\text { Percentage }\end{array}$ & Open Facility \\
\hline 179 & 1 & 11560 & 38.0 & KM \\
& 2 & 17868 & 58.7 & SD,KM \\
& 3 & 23138 & 76.0 & SD,KM,TPG \\
& 4 & 82.1 & SD,SL,KM, TPG \\
& 5 & 25009 & 87.7 & SD,SL,KM,KB,TPG \\
& & & & \\
\hline 132 & 1 & 13143 & 43.2 & SL \\
& 21228 & 69.7 & SD,KB \\
& 3 & 25612 & 84.1 & SD,KM,TPG \\
& 4 & 28379 & 93.2 & SD,SL,KB, TPG \\
& 5 & 29996 & & SD,SL,KM,KB,TPG
\end{tabular}

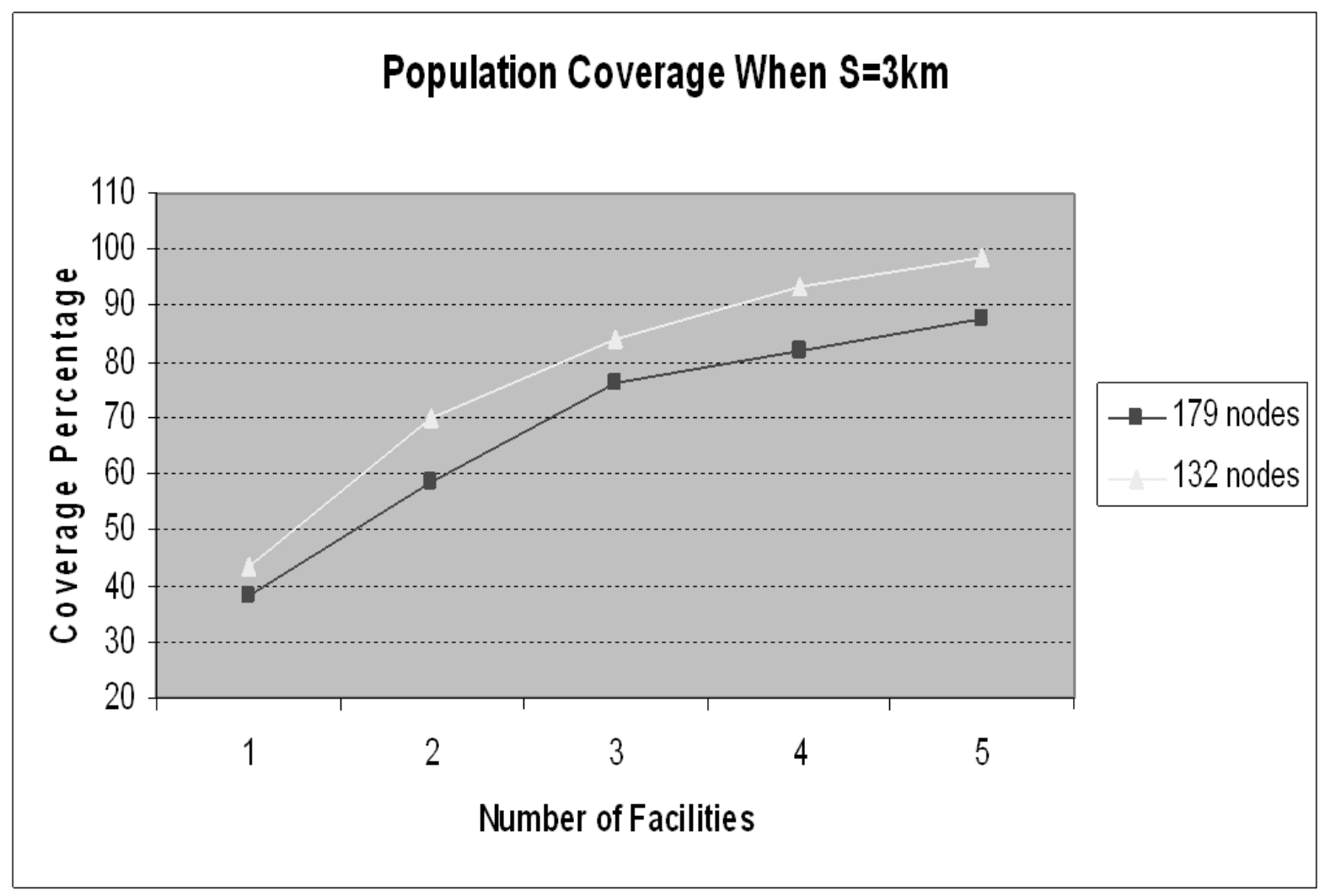

Figure 12: Trend in Coverage Percentage When $S=3 \mathrm{~km}$ 


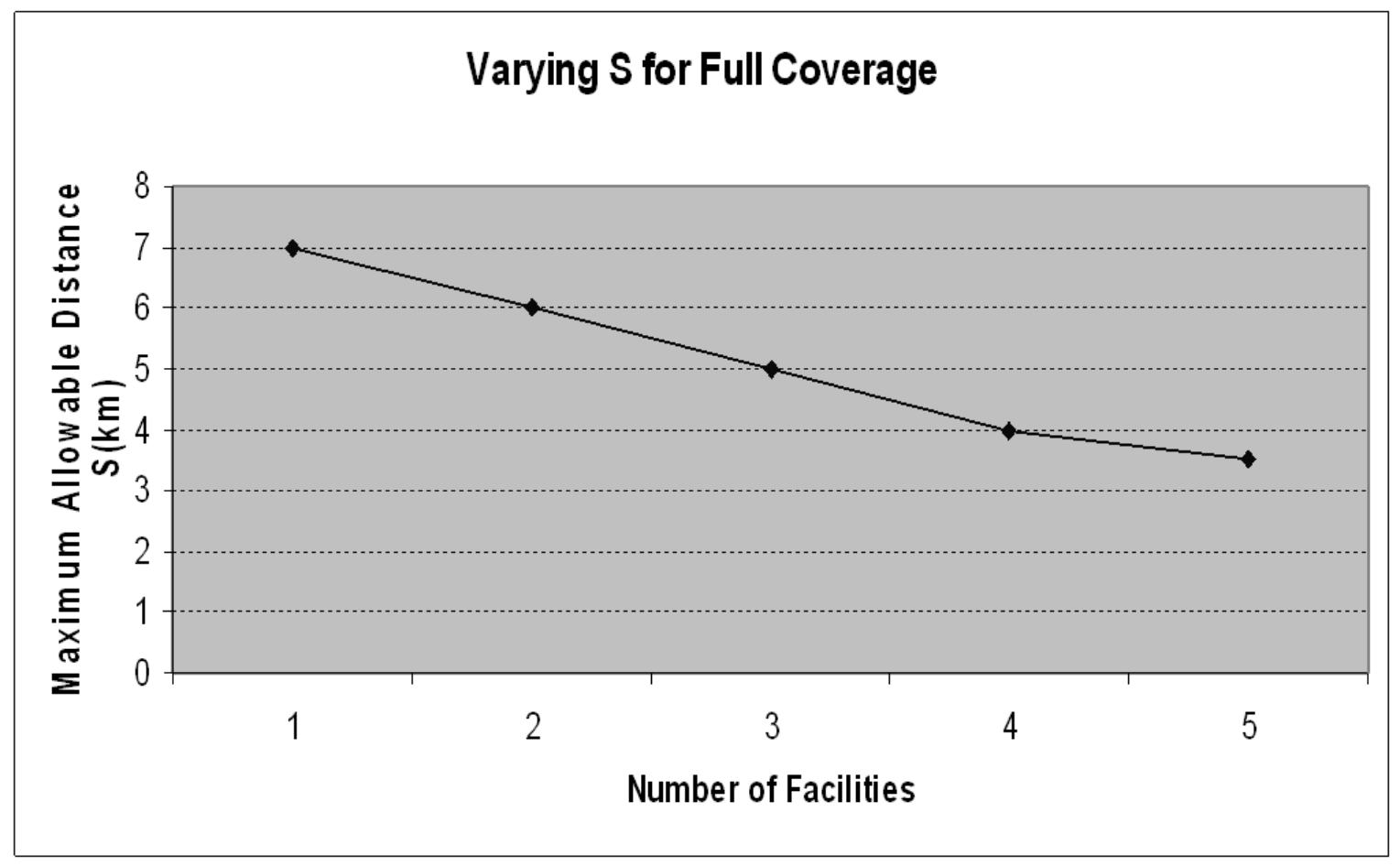

Figure 13: Maximum Allowable Distance $S$ for Full Coverage (when demand is distributed uniformly over the whole service area)

Every facility in the area is assigned a different demand volume to serve in proportion to its nominal capacity. It can be seen from Table 1, in which Facility KB and SD are assigned the demand volume 5114 and 2617 respectively. Applying the p-median and MCLP models has reassigned the demand nodes and its volume as shown in Table 9 and 10. The result of population distribution in
MCLP result is totally the opposite of the existing practice, this might due to no restriction in assigning population volume into the facility. It is noted earlier that in this study the facility is assumed to be un-capacitated. Hence it is the limitation of this study which will be addressed in the future research.

Table 9: Comparing The Number Of Demand Nodes And Volume Assignment To Each Facility (Demand Is Uniformly Distributed Within Its Own Service Boundary)

\begin{tabular}{|c|c|c|c|c|c|c|}
\hline \multirow[t]{2}{*}{$\begin{array}{l}\text { Number of } \\
\text { facilities }\end{array}$} & \multicolumn{2}{|c|}{$\begin{array}{c}\text { No model } \\
\text { (Existing assignment) }\end{array}$} & \multicolumn{2}{|c|}{$p$-median } & \multicolumn{2}{|l|}{ MCLP } \\
\hline & $\begin{array}{c}\text { Number of nodes } \\
\text { assigned }\end{array}$ & Volume & $\begin{array}{l}\text { Number of nodes } \\
\text { assigned }\end{array}$ & Volume & $\begin{array}{c}\text { Number of nodes } \\
\text { assigned }\end{array}$ & Volume \\
\hline SD & 20 & 2617 & 70 & 3255 & 105 & 10620 \\
\hline SL & 32 & 6157 & 34 & 6878 & 39 & 10626 \\
\hline KM & 26 & 6485 & 29 & 6946 & 27 & 6406 \\
\hline $\mathrm{KB}$ & 46 & 5114 & 23 & 4910 & 6 & 2060 \\
\hline TPG & 55 & 10085 & 23 & 8469 & 2 & 746 \\
\hline TOTAL & 179 & 30458 & 179 & 30458 & 179 & 30458 \\
\hline
\end{tabular}


Malaysian Journal of Science 29 (2): 98-118 (2010)

Table 10: Comparing The Number Of Demand Nodes And Volume Assignment To Each Facility (Demand Is Uniformly Distributed Within The Whole Study Area)

\begin{tabular}{|c|c|c|c|c|c|c|}
\hline \multirow[t]{2}{*}{$\begin{array}{l}\text { Number of } \\
\text { facilities }\end{array}$} & \multicolumn{2}{|c|}{$\begin{array}{c}\text { No model } \\
\text { (Existing assignment) }\end{array}$} & \multicolumn{2}{|c|}{$p$-median } & \multicolumn{2}{|l|}{ MCLP } \\
\hline & $\begin{array}{c}\text { Number of nodes } \\
\text { assigned }\end{array}$ & Volume & $\begin{array}{c}\text { Number of nodes } \\
\text { assigned }\end{array}$ & Volume & $\begin{array}{c}\text { Number of nodes } \\
\text { assigned }\end{array}$ & Volume \\
\hline SD & 20 & 2617 & 70 & 6455 & 105 & 14060 \\
\hline SL & 32 & 6157 & 32 & 7376 & 39 & 8546 \\
\hline KM & 26 & 6485 & 29 & 6005 & 27 & 6006 \\
\hline KB & 46 & 5114 & 23 & 5313 & 6 & 1386 \\
\hline TPG & 55 & 10085 & 25 & 5309 & 2 & 460 \\
\hline TOTAL & 179 & 30458 & 179 & 30458 & 179 & 30458 \\
\hline
\end{tabular}

\section{CONCLUSION}

This paper examined the efficiency of existing primary health delivery system in the study area. An assumption of demand being uniformly distributed has been categorized into two: uniformly distributed within its own service boundary and uniformly distributed within the whole study area.

The problem was formulated as a standard $p$ median and MCLP problems and the analysis was carried for various numbers of nodes, taking into account that some parts of the study area is unpopulated. The results indicate that the maximum traveled distance for the present number of facilities is less than or equal to $3 \mathrm{~km}$ (within the distance recommended under $\mathrm{MOH}$ of 5 is sufficient if the unpopulated areas are eliminated from the analysis.

Full coverage is achieved in all cases. However, $100 \%$ coverage cannot be realized if the unpopulated areas are taken into account. Applying the $p$-median and MCLP into the facility location in this area has also resulted in the reassignment of demand nodes and its volume, however, it is worth noting that all the analysis is done based on the assumption that all the facilities do not have capacity constraints. This limitation will be addressed in our future research.

\section{REFERENCES}

1. Bennet, V., Eaton D., and Church C (1982) "Selecting Sites for Rural Health Workers", Social Science and Medicine (16) 63-72

2. Church R., and Re Velle C (1974), "The Maximal Covering Location Problem." Papers of Regional Science Association (32) 101 -118.

3. Cocking C, Flessa S, and Reinelt G (2006) "Locating Health Facilities in Nouna District, Burkina Faso", Operations Research Proceedings 2005 431-436.

4. Current J, and Storbeck J (1991), "The Capacitated Maximal Covering Problem" Modeling and Simulation (12) 102-114.

5. Dokmeci V (1977) "A Quantitative Model for Regional Health Facility Systems", Management Science (24) 411-419.

6. Dokmeci V (1979), "A Multi Objective Model for Regional Planning of Health Facilities", Environment and Planning A (11) 517 - 525.

7. Eaton D, Church R., Bennett V., Damon B., and Lopez L (1981), "On Deployment of Health Resources in Rural Valle Del Cauca, Colombia", TIMS Studies in Management Science (17), 331-359.

8. Gould P and Leinbach T (1966), "An Approach to the Geographic Assignment of 
Hospital Services', Tijdschrift Voor Economy, En Soc. Geogrfie (57) 203-206.

9. Hakimi S (1964), "Optimum Locations of Switching Centers and the Absolute Centers and Medians of a Graph", Operations Research (12) 450-459.

10. Hansen P, Peeters D, and Thisse J (1980), "Location of Public Services: A Selective Method Oriented Survey", Annals of Public and Cooperative Economics (51) (Issue 1-2) 951.

11. Heller M., Cohon J. and Re Velle C. (1989), "The Use of Simulation in Validating a Multi Objective EMS Location Model", Annals of Operations Research (18) 1070-1080.

12. Interview with Clinics Personnel (2007).

13. Jabatan Kesihatan Negeri Selangor webpage:http://www.jknsel.moh.gov.my/en/ke sihatan.php?menu_id=6\&sub_menu_id=67. Retrieved by 2006

14. Mehretu A, Wittick R, and Pigozzi B (1983), "Spatial design for Basic Needs in Eastern Upper Volta', The Journal of Development Areas (7) 383-394

15. Mehretu A. (1985), "A Spatial Framework for Redressing Disparities in Rural Service Delivery Systems". Tijdschrift Voor Econousche en Socrate Geografie, (76) 363373.

16. Ministry of Health Annual Report 2005, Putrajaya, Selangor.

17. Ninth Malaysia Plan 2006-2010, (2006) Economic Planning Unit, Prime Minister's Department, Malaysia; available online

18. Oppong J. (1996), "Accommodating the Rainy Season In Third World Location Allocation Applications", Socio-Economic Planning Sciences (30), 121-137.

19. Pirkul, H., Schilling D. (1991), "The Maximal Covering Location Problem with Capacities on Total Workload", Management Science 37(2), 233-248.

20. Rahman, S (1991), "Location Allocation Modeling for Primary Health Care Provision in
Bangladesh", unpublished $\mathrm{PhD}$ thesis, University of Exeter, Exeter, UK

21. Rahman, S. and Smith D.K. (1999), "Deployment of Rural Health Facilities in A Developing Country", Journal of the Operational Research Society (50), 892-902.

22. Rahman, S. and Smith D.K. (2000), "Use of Location Allocation Models in Health Service Development Planning in Developing Nations", European Journal of Operational Research (23) 437-452.

23. Re Velle C.S. and Swain, R.W. (1970), "Central Facilities Location", Geographical Analysis (2) 30-42.

24. Rushton, G. (1987), "Selecting The Objective Function In The Location-Allocation Analyses", in: Spatial Analysis and LocationAllocation Models, eds. A Ghosh and G.Rushton (Van Nostrand Reinold, New York, 1987), 345-364.

25. Selangor State Health Office Annual Report 2005, Shah Alam, Selangor, Malaysia

26. Seventh Malaysia Plan 1996--2000, (1996) Economic Planning Unit, Prime Minister's Department, Malaysia; available online

27. Sixth Malaysia Plan 1991-1995, (1990) Economic Planning Unit, Prime Minister's Department, Malaysia; available online

28. The New Strait Times (2007), "Doctors Urged to Treat, Not Refer to Hospitals: Director General of Health Tan Sri Dr Ismail Merican", Tuesday Feb 13, p 8.

29. Tien J.M and El-Tell K (1984), “A Quasihiearchical Location Allocation Model for Primary Health Care Planning", IEEE Transactions on Systems, Man and Cybernetics, SMC-(14), 373-380.

30. Wang, L (2002) "Health outcomes in poor countries and policy options : empirical findings from demographic and health surveys" (World Bank Policy Research Working Paper, WPS2831) 